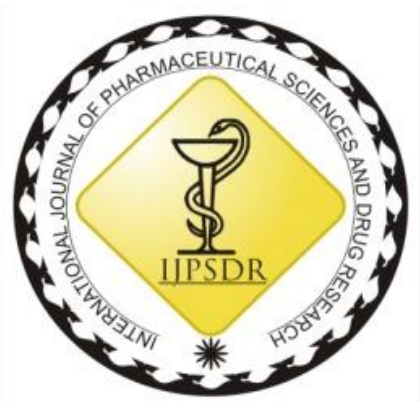

RESEARCH ARTICLE
ISSN: 0975-248X CODEN (USA): IJPSPP $(\mathrm{cc})$ EY-NC-SA

\title{
Anti-diabetic, Anti-cancer Activity and Associated Toxicity of Leucas aspera Extract in Wistar Albino Rats
}

\author{
G. C. Madhu1, Jaianand Kannaiyan², Balaji Paulraj², Veeramanikandan Veeramani1 ${ }^{*}$ \\ ${ }^{1} P G$ \& Research Centre in Microbiology, MGR College, Dr. MGR Nagar, Hosur-635109, Tamil Nadu, India \\ ${ }^{2} P G$ \& Research Centre in Biotechnology, MGR College, Dr. MGR Nagar, Hosur-635109, Tamil Nadu, India
}

Copyright (C) 2019 G. C. Madhu et al. This is an open access article distributed under the terms of the Creative Commons AttributionNonCommercial-ShareAlike 4.0 International License which allows others to remix, tweak, and build upon the work non-commercially, as long as the author is credited and the new creations are licensed under the identical terms.

\begin{abstract}
In regenerative medicine, nanotechnology plays a vital role in the diagnosis, the delivery of therapeutic drugs and the treatment of many diseases and disorders. Due to the growing need to develop environmentally friendly technologies in material synthesis, the biosynthesis of Iron Oxide Nanoparticles (IOP) has received considerable attention over the past decades. Therefore, the community is now looking back for traditional medicines for various diseases after the practice of allopathic drugs with tremendous side effects. There are an increasing number of biomedical applications for iron oxide nanoparticles; as such uses are essential for in-vitro characterisation and invivo to ensure the bio-safety of these particles. The main complication of diabetes due to frequent lipid peroxidation is liver damage and renal dysfunction, but treatment with Leucas aspera has a pronounced effect on these indicators, which protects the organs from further damage. The current research supports the traditional use of Leucas aspera against diabetes mellitus and cancer, as well as the safety, effectiveness and potency of Leucas aspera leaf extract's anti-diabetic and anti-cancer effect in the in-vivo model. The overall results reveal that Leucas aspera has the potential and can be a candidate of choice without side effect.
\end{abstract}

Keywords: Anti-diabetic activity, Diabetes mellitus, Iron oxide nanoparticles (IOP), Leucas aspera, Toxicity studies.

DOI: 10.25004/IJPSDR.2019.110617

Int. J. Pharm. Sci. Drug Res. 2019; 11(6): 387-392

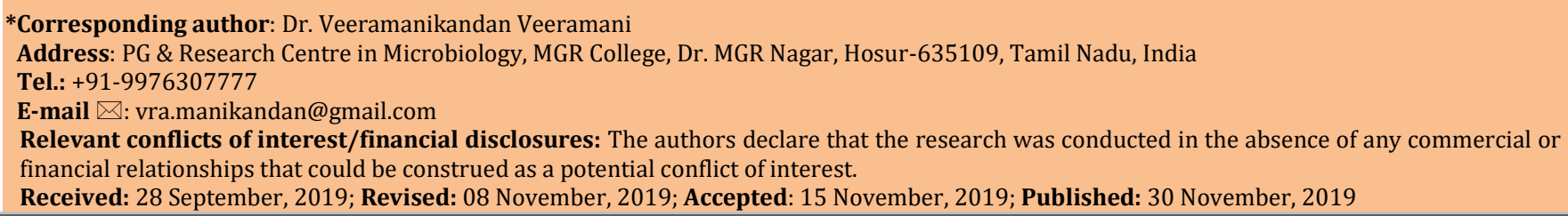

\section{INTRODUCTION}

Diabetes mellitus is an endocrine, metabolic ailment related to changes in the hormones, metabolic enzymes, lipid peroxidation resulting in liver and kidney grievance. Diabetes control begins with oral hypoglycemic agents and insulin, while different types of oral hypoglycemic agents are available along with insulin for diabetes mellitus care. [1] Due to the side effects correlated with synthetic and commercial medicinal drugs, there is increasing interest in the herbal remedies. Similarly, there is a necessity to find alternative medicines that are highly effective, affordable and accessible to the public at non-toxic levels. These all can be possible by only testing the new molecules of plant products that can be active at different dosage rates, and that is not adverse. The lyophilised form and raw extracts of the medicinal herbs are used in the treatment system of Siddha and 
Ayurveda to cure different diseases, including Cancer and Diabetes. [2] Conceivably a single compound or mixture of compounds present in the individual plant extracts contains various phytochemicals are uncertain. Besides, the herbal medicines widely prescribed even though when their biologically active components remain unclear and indefinite potential safety, undefined side effects in clinical experience.

So far, very few specific botanical medicinal plants have been identified to control diabetes dramatically, and one of them is Leucas aspera. Traditionally, this herb used as an insecticides, and antipyretic agent valued as aperitif, cough medicine, diaphoretic, insecticide, and stimulant plants. Leaves are often used for rheumatism, certain skin infections, as well as for snake bites. [3] Many research studies have experimentally demonstrated that Leucas aspera is a promising herb toward diabetes. [4] In our earlier studies, it has been proved that the biological approach to the synthesis of iron oxide nanoparticles using Leucas aspera leaf extract is an eco-friendly and cost-effective alternative to traditional chemical and physical methods and would be suitable for large scale production. [5] We also studied serum creatinine, blood urea, serum lipid profile, total protein content, enzymatic antioxidant, and non-enzymatic antioxidant assays, and demonstrated that Leucas aspera has an active antidiabetic function in diabetic rats caused by streptozotocin (STZ). [6] The aim of this study was to summarise and examine the histological analyses of liver, kidney and pancreas in order to evaluate the antidiabetic function, antitumor and anti-proliferative effects, and the safety/toxicity risk associated with the use of Leucas aspera leaf extract in diabetic rats induced by STZ. The efficacy was compared with the standard hypoglycemic drug, Glibenclamide.

\section{MATERIALS AND METHODS}

\section{Chemicals}

Streptozotocin (STZ) was imported from Sigma Chemical Co. (St. Louis, Missouri, USA) while Glibenclamide was a Taj Pharmaceuticals Ltd., India brand. Goods of Randox Laboratories Ltd, Ardmore, Co Antrim, UK were the test kits used for biochemical assays. Analytical consistency was used for all other chemicals and reagents.

\section{Plant Material and Authentication}

Throughout December 2016, Leucas aspera's whole plants were collected from MGR College, Hosur, Tamil Nadu, India. Plant materials identified and certified the collected species. Tightly packed with a polythene bag, the unearthed leaf contents were then transported to the laboratory. Then the leaves are washed once with distilled water and placed under room temperature.

\section{Preparation of Aqueous Extract}

Twenty-five grams of Leucas aspera leaves measured accurately and cleaned vigorously under flowing tap water and then treated with double distilled water to remove impurities from the ground. Using a mortar and pestle, they are smashed and finely macerated. 100 $\mathrm{ml}$ of deionised water was applied after homogenization and warmed over a water bath held for $15 \mathrm{~min}$ at $80^{\circ} \mathrm{C}$. The leaf extract was filtered through $25 \mu \mathrm{m}$ pore size Whatman No 1 filter paper and stored for further experiments in the refrigerator.

\section{Phytochemical Screening}

To determine the chemical components, Leucas aspera hot water extract was subjected to several preliminary phytochemical testing. The methodology of research used as per in the previously published paper according to standard techniques reviewed in context. [5]

\section{Biochemical profiling}

The leaf extracts of Leucas aspera estimated for the presence of various biochemical profiling assays using standard conventional protocols studied in detail in the earlier published methodology. [6]

\section{Experimental animal}

Experiments are done using either Wistar albino rat gender weighing between 150 and 200 grams. Rats had regular laboratory chow (Hindustan Lever Ltd., Mumbai, India) and water ad libitum. The studies planned and performed in compliance with the academic protocols (688/PO / Re /S/02/CPCSEA), NCP / IAEC/2017-18/16 in-vivo study.

\section{Induction of Diabetes in Rats}

Diabetes stimulated in 12 hours fasted either by a single intraperitoneal Streptozotocin injection (50 mg/ kg) dissolved in $0.1 \mathrm{M}$ of citrate solution $(\mathrm{pH} 4.5)$, accompanied by Streptozotocin (120 $\mathrm{mg} / \mathrm{kg})$ intraperitoneal administration after 15 minutes. Blood Glucose rate assessed after 72 hours of activation using a single-touch pick glucometer and verified diabetes. Experimental Design

After the successful induction of experimental diabetes, the rats divided into five groups of each five rats. Group I (Control 0.1 pct CMC): Normal rats received 0.1 pct Carboxy Methyl Cellulose Solution $(1 \mathrm{mg} / \mathrm{kg})$ as through oral route. Group II (Diabetic Control): STZinduced diabetic rats-Streptozotocin-left uncontrolled. Group III (Reference Control): Glibenclamide-treated diabetic rat $(5 \mathrm{mg} / \mathrm{kg}$ ) induced by streptozotocin. Group IV (Compound C 200): STZ-induced diabetic rat rats treated with Leucas aspera leaf compound 200 $\mathrm{mg} / \mathrm{kg}$ obtained in hot water. Group V: (Compound C 400): STZ rats - Streptozotocin-induced diabetic rats treated with Leucas aspera leaf compound $400 \mathrm{mg} / \mathrm{kg}$ obtained from hot water. All the test compounds and the reference drug Glibenclamide administered once daily for 14 days through an oral route using gastric gavage tubes.

\section{Collection of Blood Sample}

A glucometer is used to measure blood collected from the tail vein on $0,4,7$ or 14 days of opioid treatment and glucose levels. The rats were fasted overnight at the start of the experimental duration, anaesthetized with Pentobarbitone sodium $(60 \mathrm{mg} / \mathrm{kg}$, i.p $)$ anaesthesia, and the blood was obtained through a 
retro-orbital puncture in non-heparinized channels. Blood samples were kept at room temperature for 30 minutes to collect serum and centrifuged at $3000 \mathrm{Xg}$ for 10 minutes, and the supernatant was taken to evaluate lipid profiles, liver function (AST, ALT and ALP) and kidney function examinations.

\section{Sacrifice study}

The rats are instantly robbed immediately, slaughtered by decapitation, gathering the blood with and without anticoagulant. To calculate for the antioxidant quality, tissue samples are subsequently dissected, cleaned, dried and measured.

\section{Acute toxicity studies}

An acute toxicity test was performed according to the recommendations of the OECD-423 (Organization of Economic and Cooperation Development). Wistar albino rat were selected in this study using a random sampling methodology. The rats fast with ample exposure to food for four hours. When death was observed in two out of three species, the dosage noted was known to be a toxic dose.

Nevertheless, if only one individual out of three animals met death, the same dosage was replicated to validate the toxic effect. If there was no mortality, higher doses $(50,300,2000 \mathrm{mg} / \mathrm{kg}$ ) of the different Leucas aspera leaf extracts were used for more toxicity tests. The general activity found during the study of acute toxicity [7] such as sedative, hypnotic, coma, ptosis, analgesia, stupar response, physical function, soothing muscle, piloerection, skin colour shift, lacrimal secretion, and stool consistency.

\section{Histopathology}

Animals are abused by decapitation under mild ether anaesthesia. The appropriate liver and kidney organs are dissected and extracted in 10\% formalin solution and treated by the paraffin technique immediately. Sections of $5 \mu$ thickness for histopathological analysis are cut and coloured haematoxylin and eosin (H \& E).

\section{Statistical Analysis}

Statistics displayed a mean \pm SEM. The statistics tested used a one-way variance analysis (ANOVA) followed by a ' $t$ ' test by Dunnett using version 3 of GraphPad. $P$ values $<0.05$ have been deemed important.

Table 1: Oral acute toxicity study of $L$. aspera $(2000 \mathrm{mg} / \mathrm{kg})$ in mice

\begin{tabular}{ccc}
\hline S. No. & General Behaviour & Hot Water Extract \\
\hline 1. & Sedation & $(-)$ \\
2. & Hypnosis & $(-)$ \\
3. & Convulsion & $(-)$ \\
4. & Ptosis & $(-)$ \\
5. & Analgesia & $(-)$ \\
6. & Stupar Reaction & $(-)$ \\
7. & Motor activity & $(-)$ \\
8. & Muscle Relaxant & $(-)$ \\
9. & CNS Stimulant & $(-)$ \\
10. & CNS Depressant & $(-)$ \\
11. & Pilo Erection & $(-)$ \\
12. & Skin Colour & $(-)$ \\
13. & Lacrimation & $(-)$ \\
14. & Stool Consistency & $(-)$ \\
\hline
\end{tabular}

(+) Present; (-) Absent

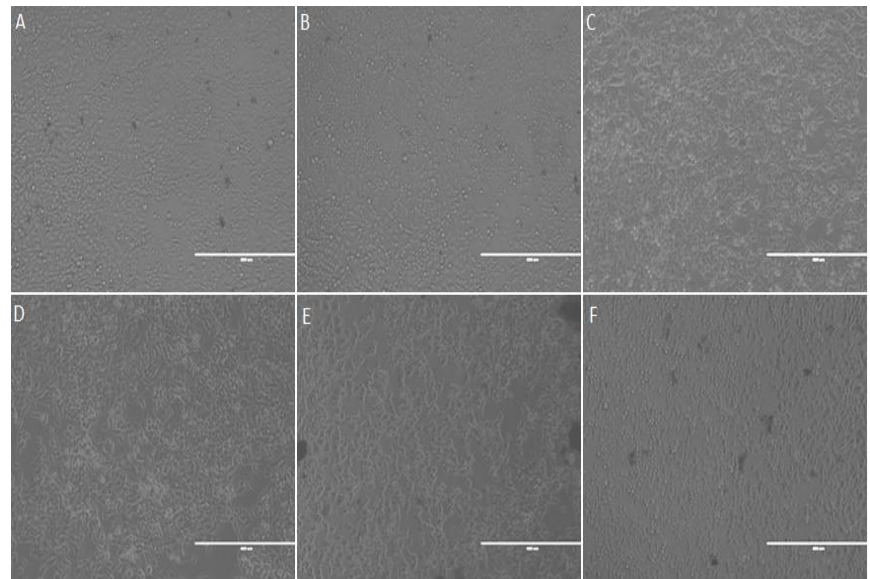

Fig. 1: Microscopic images of HeLa Cells on Treatment with Different concentration of Iron Oxide particle

Microscopic images (viewed under $10 \mathrm{X}$ objective) of HeLa cells treated with different concentration Iron Oxide particles (IOP) A: HeLa + 10ug/ml IOP, B: HeLa + 50ug/ml IOP, C: HeLa+ 100ug/ml IOP, D: HeLa + 250ug/ml IOP, E: HeLa + 500ug/ml IOP, F: HeLa+ $1000 \mathrm{ug} / \mathrm{ml}$ IOP. EVOS Fluroscence Microscope

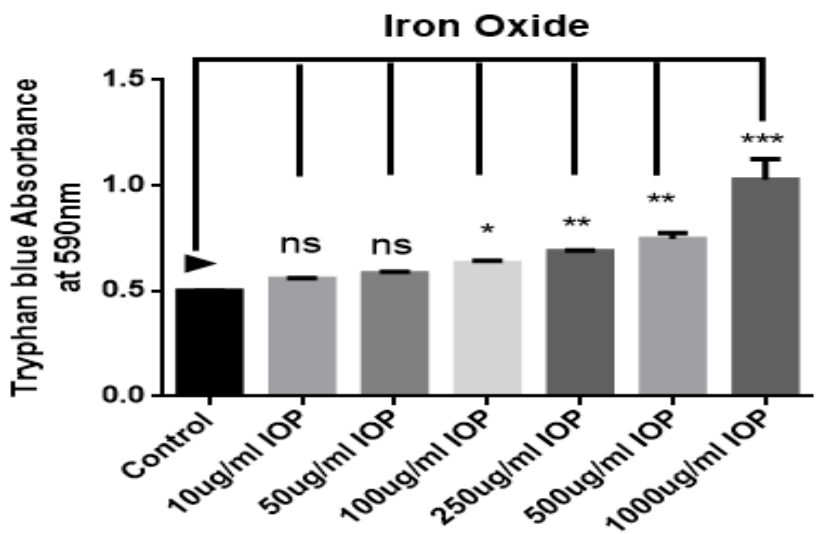

Fig. 2: Trypan Blue assay- Multi-well Absorbance at 590nm (TECAN)

Tryphan blue assay- absorbance read at $590 \mathrm{~nm}$ of HeLa cells treated with different of Iron Oxide Particle (IOP); N=3. One way ANOVA followed by Dunnett's multiple comparison tests was performed to analyse the level of significance $P<0.05$ was considered significant. All groups were compared with control.

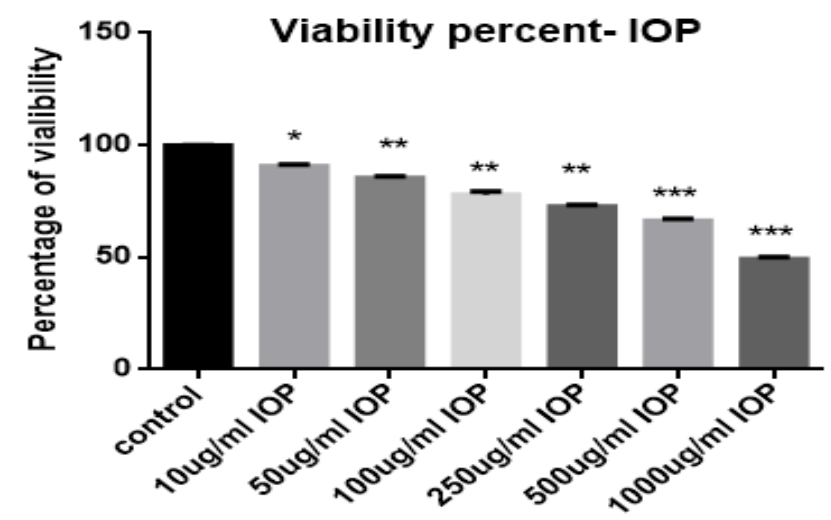

Fig. 3: Viability percentage of HeLa cells treated with Iron oxide particles (IOP)

Tryphan blue assay- percentage viability of HELA cells treated with different of IOP (\% calculated from the absorbance OD value 590nm); N=3. One way ANOVA followed by Dunnett's multiple comparison test was performed to analyse the level of significance $P<0.05$ was considered significant. All groups were compared with control. 


\section{RESULTS AND DISCUSSION}

Leucas aspera plants are considered as traditionally important for their medicinal properties such as Antifungal, Antioxidant, Anticancer, Phytotoxic, Antivenom, Hepatoprotective, Anti-inflammatory, Anti-nociceptive, Antiulcer, Antimalarial and Antidiabetic activity. All parts of the plants like the leaves, flowers, stem and root of this plant has the pharmacological activities.

Plant-derived medicines attracted increasing interest since the last couple of decades because of their potent pharmacological activities, convenience to users, economic viability and low toxicity. Leucas aspera is a herb used in Ayurveda because of anti-rheumatic, antipyretic, anti-inflammatory, antibacterial, anticancer, and cytotoxic function. ${ }^{[8]}$ In fact, allopathic drugs that are available commercially are quite dangerous and harmful. In this scenario, we searched for new antimicrobial agents from various medicinal plants with no cytotoxic impact and realised findings from the acute toxicity experiment reflected the non-toxic nature of the Leucas aspera extracts with no lethality or any harmful reactions detected at any of the selected doses until the end. Hence we studied; Leucas aspera directly evaluated the increased behaviour of its nanoparticles in cancer cells and healthy cells of HeLa.

As a piece of evidence, our previous findings on $L$. aspera reported that for antibacterial action and antioxidant tests, synthesised iron oxide nanoparticles were effectively employed. [5,9] Besides, we also assessed the anti-diabetic ability of Leucas aspera leaf extract in Streptozotocin-induced Wistar albino rats to demonstrate potency and efficacy by biochemical profiling such as serum creatinine, blood urea, serum lipid profile, total protein content, enzymatic antioxidant, and non-enzymatic antioxidant assays. [6] To conclude all the aspects, we expanded this experiment to evaluate the safety, effectiveness, efficiency and potential accessibility in the in-vivo system of Liver, Kidney and Pancreas. The cytotoxicity of the plant extract has also been studied which could be used as anticancer therapy.

Oral acute toxicity study of $L$. aspera extract $(2000$ $\mathrm{mg} / \mathrm{kg}$ ) in mice

Initially, the Leucas aspera leaf extract was administered orally at a dose of $5 \mathrm{mg} / \mathrm{kg}$ and, observed for three days, for mortality if any. The observed results for acute toxicity study of Leucas aspera hot water extract were tabulated in Table 1. With the L. aspera leaf extract, there was no mortality. Also, at $2000 \mathrm{mg} / \mathrm{kg}$ hot water extract from L. aspera leaf after 24 and 72 hours also did not alter any of the overall habits. Furthermore, there was no lethality, or a toxic reaction was found during and, after the study period with the leaf extracts $L$. aspera.

Anti-cell proliferation activity and Cytotoxicity Assay for Iron Oxide

Leucas aspera extracts have been checked for proliferative anti-cell activity. In HeLa cervical cancer cell lines, the cell-killing activity of these compounds was evaluated. Cells are treated for 24 hours with various IOP extract concentrations from 10 to $1000 \mu \mathrm{g} / \mathrm{ml}$.
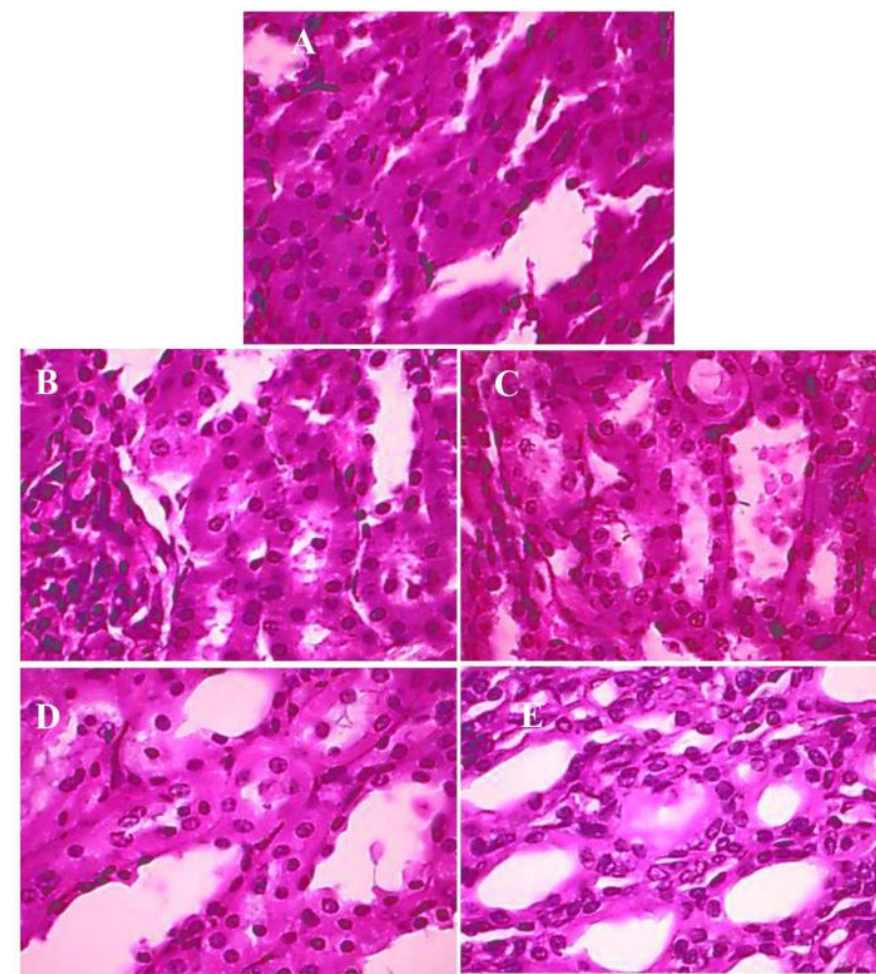

Fig. 4: Histological investigation of Liver

In-vivo study of Liver. A: Control (0.1\% CMC), B: Diabetic Control, C: Reference Control (Glibenclamide), D: Compound C 200 (Hot Water Extract (200 mg)), E: Compound C 400 (Hot Water Extract (400 mg)).
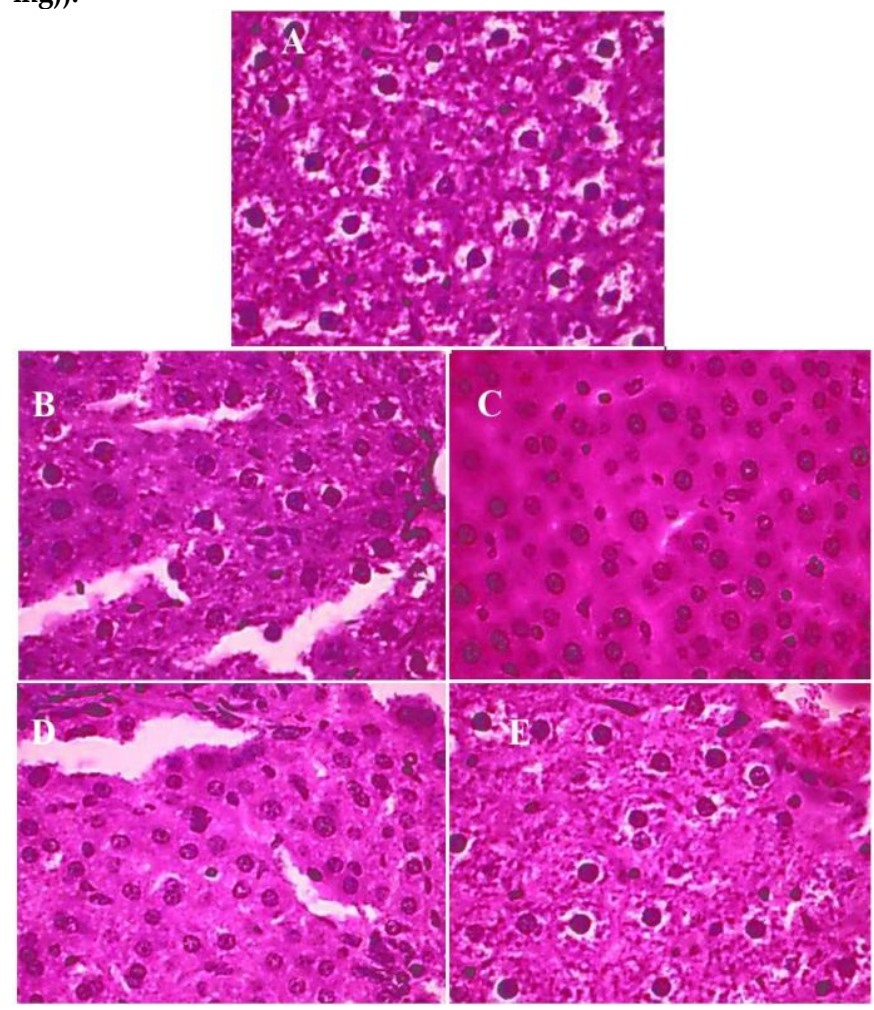

Fig. 5: Histological investigation of Kidney

In-vivo study of kidney. A: Control (0.1\% CMC), B: Diabetic Control, C: Reference Control (Glibenclamide), D: Compound C 200 (Hot Water Extract (200 mg)), E: Compound C 400 (Hot Water Extract (400 mg)). 


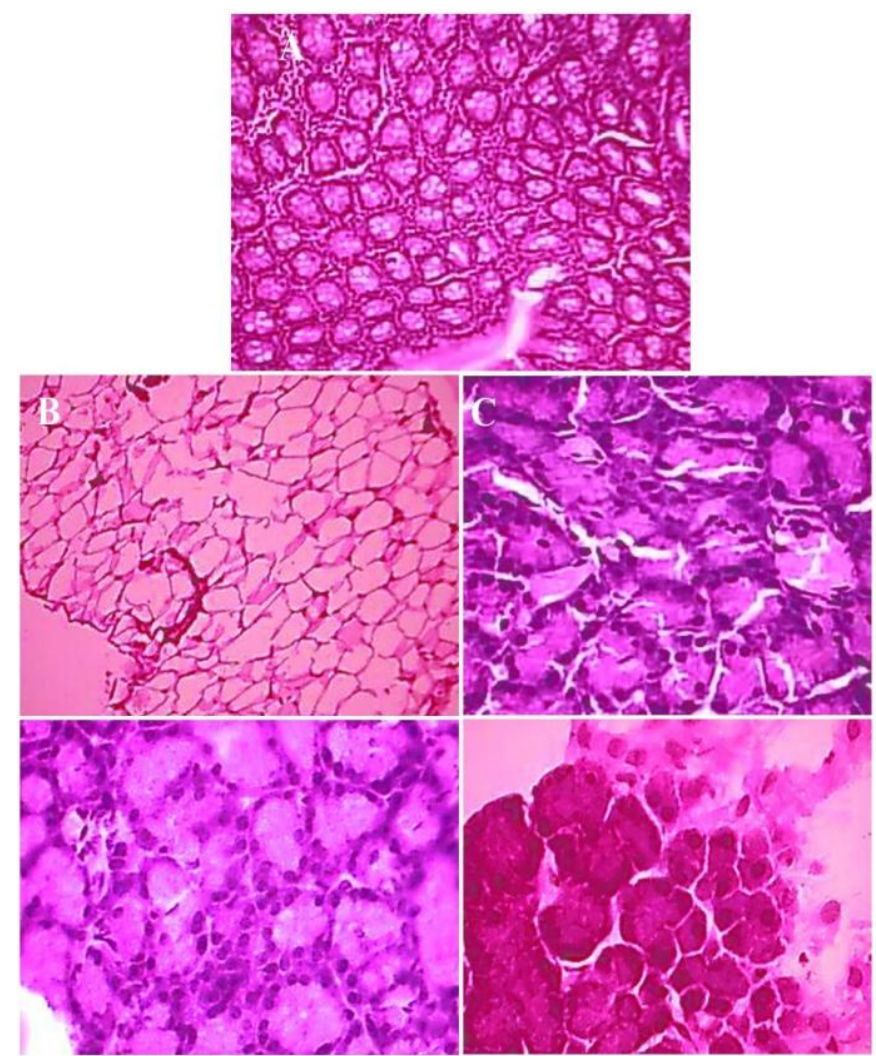

Fig. 6: Histological investigation of Pancreas

In-vivo study of Pancreas. A: Control (0.1\% CMC), B: Diabetic Control, C: Reference Control (Glibenclamide), D: Compound C 200 (Hot Water Extract (200 mg)), E: Compound C 400 (Hot Water Extract (400 mg)).

It was observed that cell survival rates decreased in a dose-dependent manner, and the concentrations needed to inhibit cell growth in HeLa cell lines by $50 \%$ $\left(\mathrm{IC}_{50}\right)$ varied for the different IOP concentrations. At $250 \mu \mathrm{g} / \mathrm{ml} \mathrm{L}$. aspera concentration, there is gradual cell death. I.e., HeLa cell lines' survival rate was adversely correlated with the intensity of the extract indicating the dose-dependent inhibition of cervical cancer cells. Cytotoxic studies on the HeLa cervical cancer cell lines showed that the IOP extracts of $L$. aspera were able to inhibit the growth of tumour cells, while within the range of concentration between 50 to $1000 \mu \mathrm{g} / \mathrm{ml}$, the IOP extracts of L. aspera could cause only 10 to $20 \%$ mortality at this range of concentration (Fig. 1).

\section{Cell viability by nanoparticle exposure}

Viability in response to nanoparticles was evaluated by Trypan blue exclusion for HeLa cells exposed to nanoparticles over seven days. After $24 \mathrm{~h}$ incubation with IOP up to $5 \%$ to $30 \%$ reduction in viability was observed in HeLa cell lines respectively at $10 \mu \mathrm{gmL}$, $50 \mu \mathrm{gmL}, 100 \mu \mathrm{gmL}, 250 \mu \mathrm{gmL}, 500 \mu \mathrm{gmL}$ and $1000 \mu \mathrm{gmL}$. As evidenced by the data analysed in Figure 2 and in Figure 3, the IOP leaf extracts of $L$. aspera had both antitumor and anti-proliferative effects. The untreated cells showed normal morphology, while cells treated with the L. aspera extracts showed morphological variations occurring in the cells like blubbing of the cell membrane and shrinkage of cells (Fig. $1 \mathrm{~A}$ to F). The results indicated that cytotoxic effects of the IOP $L$. aspera extracts might have acted through the induction of apoptosis in cells.

Histological investigation of Liver, Kidney and Pancreas

The histopathological study of the liver of streptozotocin-induced Wistar albino rats with the leaf extracts of L. aspera (Fig. 4) reveals that the section of the normal control showed normal liver architecture with normal portal triad and mild central vein congestion. Section of the Diabetic control showed the liver tissue with a slight alteration of liver architecture, periportal inflammation, widening of sinusoids, and normal Kupfer cell activity. Glibenclamide treated section showed liver with preservation of liver architecture, prominent central vein, increased Kupfer cell activity and widening of sinusoids. Hot water extracts of the L. aspera leaves at low concentration (200 $\mathrm{mg}$ ) showed liver architecture, severe central vein congestion and mild periportal inflammation whereas the high concentration $(400 \mathrm{mg}$ ) of the same showed liver tissue with distorted liver architecture, and central vein congestion and periportal inflammation observed.

The histopathological study of the kidney of streptozotocin-induced Wistar albino rats with different leaf extracts of L. aspera (Fig. 5) reveals that the section of the normal control kidney showed hypercellular glomeruli, thick-walled congested blood vessels, congested proximal convoluted tubules and distal convoluted tubules. Section of the Diabetic control showed the kidney tissue with normal glomeruli with normal proximal convoluted tubules and distal convoluted tubules with normal vascularity. Glibenclamide treated section showed kidney with normal glomeruli, mildly increased vascularity, some the tubules showing hydropic degeneration. Hot water extracts of the L. aspera leaves at low concentration (200 $\mathrm{mg}$ ) showed kidney with hypercellular glomeruli, congested blood vessels in the interstitium with inflammation and normal tubules whereas the high concentration (400 mg) of the same showed kidney with few congested hypercellular glomeruli, normal proximal convoluted tubules and distal convoluted tubules with minimal inflammation of the interstitium was observed.

The histopathological study of Pancreas of streptozotocin-induced Wistar albino rats with leaf extracts of L. aspera (Fig. 6) reveals that the section of the normal control pancreas showed normal pancreatic acini with dilated ducts, mild stratification, thickwalled congested blood vessels and occasional islet cells. Section of the Diabetic control showed the pancreatic acini with decreased islet cells, peripancreatic adipose tissue with inflammation and congested blood vessels. Glibenclamide treated section showed lobules of pancreatic acini with few thick walled ducts and congested blood vessels. Hot water extracts of the L. aspera leaves at low concentration (200 $\mathrm{mg}$ ) showed pancreatic acini with few nests of islet cells, occasional dilated ducts, and mild periductal 
inflammation and congested blood vessels whereas the high concentration (400 $\mathrm{mg}$ ) of the same showed pancreatic acini with congested blood vessels and decreased islet cell collection was observed.

In conclusion, our study demonstrates that hot water leaf extract of L. aspera has a promising antioxidant and antibacterial effect of using for human health. The hot water extract also has a very prominent cytotoxic effect to be used in many pharmacological as well as biological actions. Consequently, the pharmacological and toxicity studies are also proved the anti-diabetic and anti-cancer potential of $L$. aspera could be the promising source of therapeutic demands.

\section{REFERENCES}

1. Taofik O Sunmonu and Anthony J Afolayan. Evaluation of anti-diabetic activity and associated toxicity of artemisia afra aqueous extract in Wistar rats. Evidence-Based Complementary and Alternative Medicine. 2013; Article ID 929074: 1-8.

2. Sidhra SZA, Syed ZAK, Krishnaveni R, Anupriya B, Senthil $\mathrm{KB}$, Kishore RK. Modulatory effect of Leucas aspera on oxidative stress and glucose metabolism against diabetic complications in experimental rats. International Research Journal of Pharmacy. 2017; 8(8):27-33.

3. Srinivasan R, Ravali B, Suvarchala P, Honey A, Tejaswini A, Neeraja P. Leucas aspera - Medicinal plant: A review,
International Journal of Pharma and Biosciences. 2011; 2(1): 153-159.

4. Abdul M, Hirak D, Mohibur R, Jerin J, Aziza S, Mahabuba R, Shahnaz R, Majeedul H.C, Mohammed R. Antihyperglycemic activity evaluation Leucas aspera (Wild.) Link leaf and stem and Lannea coromandelica (Houtt.) Merr. Bark extract in mice. Advances in Natural and Applied Sciences. 2010; 4(3): 385-388.

5. Veeramanikandan V, Madhu G, Pavithra V, Jaianand K and Balaji P. Green synthesis, characterization of iron oxide nanoparticles using Leucas aspera leaf extract and evaluation of antibacterial and antioxidant studies. International Journal of Agriculture Innovations and Research. 2017; 06(02):242250.

6. Madhu GC, Jaianand K, Rameshkumar K, Balaji P, Veeramanikandan V. In-vivo studies on anti-diabetic potential of Leucas aspera in streptozotocin induced diabetic wistar albino rats. Journal of Drug Delivery and Therapeutics. 2019; 9(4-s):105-110.

7. Ecobichon DJ. The basis of toxicology testing. CRC Press, New York, 1997; Pp. 43-86.

8. Subhan AM, Shaik AN, Saritha M, Krishna TT, Malaka VJK, Chippada AR. Phytochemical screening and antihyperglycemic activity of Heliotropium indicum whole plant in Streptozotocin induced diabetic rats. Journal of Applied Pharmaceutical Science. 2014; 4 (12): 65-71.

9. Madhu GC, Jaianand K, Rameshkumar K, Eyini M, Balaji P, Veeramanikandan V. Solanum Tuberosum extract mediated synthesis and characterization of iron oxide nanoparticles for their antibacterial and antioxidant activity. Journal of Drug Delivery and Therapeutics. 2019; 9(1):5-15. 